\title{
PERKEMBANGAN HIDUP DAN DAYA MEMANGSA CURINUS COERULEUS MULSANT PADA BEBERAPA KUTU TANAMAN
}

\author{
Nur $\operatorname{Yasin}^{1}$
}

\begin{abstract}
The biological development and feeding ability of Curinus coeruleus Mulsant on several phytophthires. The research was conducted to investigate the survival and feeding capability of Curinus coeruleus Mulsant on Heteropsylla cubana, Aleurocanthus spiniferus, Planococcus citri, and Aspidiotus destructor. The research was done in completely randomized design with eight replications. The result showed that $C$. coeruleus could not survive on $A$. spiniferus. The head width of C. coeruleus larvae did not differ significantly in A. destructor, P. citri, or H. cubana. The head width increase of C. coeruleus larvae feeding on A. destructor followed Dyar's law with growth ratio of 1,4. Larval stadium of $C$. coeruleus, imago stadium, longevity, and the number of consumed preys were affected by phytophthires species. C. coeruleus could feed on more $H$. cubana than A. destructor, or P. citri.
\end{abstract}

Key words: Curinus coeruleus, phytophthires, prey, predator

\section{PENDAHULUAN}

Kutu loncat lamtoro, Heteropsylla cubana Crawford, merupakan hama eksotik bagi Indonesia (Oka \& Bahagiawati, 1986). Untuk menanggulangi serangan hama itu, pemerintah Republik Indonesia telah membentuk Tim Kerja Nasional Penanggulangan Hama Kutu Loncat Lamtoro (TKNPHKLL).

Pengendalian HKLL yang dilakukan di Indonesia pada dasarnya adalah penjabaran sistem pengendalian hama terpadu. Komponen-komponen pengendalian ini antara lain penggunaan predator yang dipadukan dengan pestisida. Usaha pengendalian dengan predator dilakukan dengan cara mendatangkan predator, Curinus coeruleus Mulsant dan Olla abdominalis Say, dari luar negeri (Hawai) (TKNPHKLL, 1987).

Pada bulan Agustus 1986, secara bertahap sudah didatangkan imago C. coeruleus sebanyak 8.300 ekor, untuk selanjutnya dibiakkan dan dilakukan pelepasan predator di lapangan (TKN-PHKLL, 1987). Aktivitas pelepasan $C$. coeruleus ini kemudian dihentikan beberapa tahun setelah pelepasan yang pertama predator impor tersebut (Sosromarsono, 2005).

Walaupun maksud impor predator tersebut adalah untuk penanggulangan HKLL, tetapi sebenarnya sifat biologi $C$. coeruleus Mulsant adalah tidak "host specific" (Soehardjan \& Oka, 1987). Informasi tentang biologi (kehidupan) musuh alami (Hoy, 1985) dan kajian tentang daya mangsa musuh alami (Shepard \& Herzog, 1985) merupakan kunci utama dalam pengendalian hayati yang efektif. Penelitian ini ditujukan untuk mempelajari perkembangan hidup dan daya mangsa $C$. coeruleus pada beberapa phytophthires (kutu-kutu tanaman) sebagai mangsa yaitu kutu loncat lamtoro Heteropsylla cubana Crawford, kutu medalion jeruk Aleurocanthus spiniferus Quaintance, kutu dompolan jeruk Planococcus citri Risso, dan kutu perisai Aspidiotus destructor Signoret.

\section{METODE PENELITIAN}

Kurungan Biakan. Curinus coeruleus dibiakkan dalam kurungan biakan yang dibuat dari kawat dan bambu sebagai kerangka kurungan serta plastik bening di sekeliling kurungan. Bagian atas kurungan ditutup dengan kain kasa. Untuk mempermudah pengambilan dan pemasukan bahan ke dalam kurungan, bagian tengah sisi kurungan dilubangi (garis tengah $10 \mathrm{~cm}$ ). Lubang ditutup dengan kain kasa. Kurungan biakan yang digunakan untuk memelihara kutu tanaman dibuat dengan bentuk dan bahan yang sama dengan kurungan biakan C. coeruleus, dengan tinggi $30 \mathrm{~cm}$ dan diameter $30 \mathrm{~cm}$ pada bagian bawah dan atas kurungan.

Pembiakan Mangsa dan Predator. Kutu dompolan Planococcus citri dibiakkan secara massal pada umbi kentang. Serangga ini bersifat polifag dan menyukai tunas umbi kentang. Planococcus citri diambil dari dompolan buah kopi yang ada di lapangan (di pohon kopi), kemudian dipindahkan pada tunas umbi

\footnotetext{
${ }^{1}$ Dosen Jurusan Proteksi Tanaman, Fakultas Pertanian, Universitas Lampung

Jl. Prof. Sumantri Brojonegoro No. 1 Bandar Lampung 35145
} 
kentang. Pada tunas umbi kentang ini kutu tanaman berkembang-biak sehingga populasinya cukup banyak.

Kutu perisai $A$. destructor dibiakkan pada buah waluh yang sudah matang. Kutu ini juga bersifat polifag dan berkembang cukup baik pada buah waluh. Buah waluh yang digunakan mempunyai permukaan kulit luar yang cukup luas sehingga kutu tanaman tersebut dapat menyebar dan hidup dalam jumlah yang cukup banyak. Lapisan kulit luar buah waluh cukup tebal dan tidak mudah membusuk sehingga dapat tahan cukup lama bila digunakan untuk tempat hidup kutu tanaman tersebut.

Kutu A. destructor diperoleh dari daun kelapa yang menunjukkan gejala terserang kutu dengan populasi kutu yang cukup banyak. Daun kelapa tersebut kemudian ditempatkan pada kulit luar buah waluh. Setelah ditunggu beberapa minggu maka kulit buah waluh dipenuhi oleh kutu tanaman yang berasal dari daun kelapa.

Kutu A. spiniferus dan $H$. cubana tidak dibiakkan di laboratorium, tetapi diambil dari lapangan. Populasi kutu ini tersedia cukup banyak di lapangan pada tanaman lamtoro.

Predator C. coeruleus diperoleh dari lapangan di pertanaman lamtoro. Sebanyak 25 pasang kumbang jantan dan kumbang betina dipelihara dalam kurungan plastik (tinggi $80 \mathrm{~cm}$ dan garis tengah $30 \mathrm{~cm}$ ) dan diberi pakan atau mangsa yang terdiri atas 4 jenis kutu tanaman. Perkawinan kumbang jantan dan betina menghasilkan telur yang digunakan untuk bahan penelitian.

Tempat peletakan telur predator disediakan dengan meletakkan jeruji bambu yang disayat miring di tepi kiri dan kanannya di dalam kurungan plastik. Kaleng berisi tanah yang diletakkan dalam kurungan digunakan sebagai tempat menancapkan bambu dan bahan lainnya untuk tempat pakan bagi kumbang.

Pelaksanaan Penelitian. Telur-telur $C$. coeruleus yang dihasilkan dari perkawinan dipindahkan ke dalam cawan petri yang sudah diberi alas 2 lembar kertas saring. Dalam satu cawan petri dimasukkan 5 butir telur. Untuk menjaga kelembaban, di dalam cawan petri diberi gumpalan kapas kecil yang ditetesi air.

Larva instar ke satu dari hasil penetasan kemudian dipisahkan ke dalam masing-masing petri untuk perlakuan. Satu cawan petri berisi satu ekor larva $C$. coeruleus. Oleh karena itu larva yang digunakan sebanyak $32(=4 \times 8)$ ekor. Pada saat awal setiap larva diberi mangsa 15 ekor kutu tanaman untuk masing-masing perlakuan. Jumlah kutu tanaman yang dimangsa dihitung setiap hari dan sisanya dibuang untuk diganti dengan kutu yang baru. Makin lama umur predator jumlah mangsa yang diberikan makin banyak. Pemberian mangsa dilakukan sampai predator mati.

Peubah Amatan. Dalam penelitian ini dilakukan pengamatan terhadap: (1) Lebar kepala larva setiap instar C. coeruleus. Pengukuran lebar kepala dilakukan setelah proses ganti kulit dengan menggunakan kertas milimeter blok, dengan satuan mm. (2) Stadium larva, yaitu jangka waktu sejak telur menetas sampai mulai terbentuk pupa, dengan satuan hari. (3) Stadium imago, yaitu jangka waktu sejak kumbang muncul dari pupa sampai mati, dengan satuan hari. (4) Lama hidup C. coeruleus, yaitu lamanya waktu sejak telur menetas sampai imago yang berasal dari telur itu mati, dengan satuan hari. (5) Jumlah kutu tanaman yang dimangsa oleh C. coeruleus selama hidupnya dari masing-masing perlakuan, dengan satuan ekor.

\section{HASIL DAN PEMBAHASAN}

Hasil yang diperoleh dari penelitian menunjukkan bahwa kutu medalion jeruk (A. spiniferus) yang digunakan sebagai perlakuan mangsa predator, $C$. coeruleus, masih dalam keadaan utuh; dengan kata lain A. spiniferus tidak dimangsa oleh larva $C$. coeruleus. Seluruh larva $C$. coeruleus yang diberi mangsa kutu tersebut akhirnya mati pada saat instar pertama. Oleh karena itu, selanjutnya perbandingan peubah amatan dilakukan terhadap ketiga perlakuan kutu lainnya yaitu $A$. destructor, $P$. citri, dan H. cubana.

Lebar Kepala. Lebar kepala larva instar pertama C. coeruleus sampai dengan instar ke empat yang diberi makanan dari masing-masing jenis kutu tanaman (A. destructor, $P$. citri, dan $H$. cubana) tidak berbeda nyata (Tabel 1, 2, 3, dan 4). Hal ini mengandung makna bahwa ketiga jenis kutu tanaman yang digunakan sebagai bahan pengujian memberikan 
Tabel 1. Uji nilai tengah untuk pengaruh perlakuan terhadap lebar kepala larva Curinus coeruleus instar pertama

\begin{tabular}{lc}
\hline Perlakuan & Nila tengah $(\mathrm{mm})$ \\
\hline Aspidiotus destructor & $0,3^{\mathrm{a}}$ \\
Planococcus citri & $0,2^{\mathrm{a}}$ \\
Heteropsylla cubana & $0,2^{\mathrm{a}}$ \\
\hline
\end{tabular}

Nilai tengah yang diikuti dengan huruf yang sama pada kolom yang sama tidak berbeda nyata (uji BNT, $\alpha=0,05$ ).

Tabel 2. Uji nilai tengah untuk pengaruh perlakuan terhadap lebar kepala larva C. coeruleus instar kedua

\begin{tabular}{lc}
\hline Perlakuan & Nilai tengah $(\mathrm{mm})$ \\
\hline Aspidiotus destructor & $0,3(35,8)^{\mathrm{a}}$ \\
Planococcus citri & $0,4(36,5)^{\mathrm{a}}$ \\
Heteropsylla cubana & $0,3(33,3)^{\mathrm{a}}$ \\
\hline
\end{tabular}

Angka dalam kurung adalah hasil transformasi $\operatorname{arc} \sin \sqrt{x}$.

Nilai tengah yang diikuti dengan huruf yang sama pada kolom yang sama tidak berbeda nyata (uji BNT, $\alpha=0,05$ ).

Tabel 3. Uji nilai tengah untuk pengaruh perlakuan terhadap lebar kepala larva C. coeruleus instar ketiga

\begin{tabular}{lc}
\hline Perlakuan & Nila tengah $(\mathrm{mm})$ \\
\cline { 1 - 2 } Aspidiotus destructor & $0,5(43,8)^{\mathrm{a}}$ \\
Planococcus citri & $0,5(45,2)^{\mathrm{a}}$ \\
Heteropsylla cubana & $0,4(41,3)^{\mathrm{a}}$ \\
\hline
\end{tabular}

Angka dalam kurung adalah hasil transformasi $\operatorname{arc} \sin \sqrt{x}$.

Nilai tengah yang diikuti dengan huruf yang sama pada kolom yang sama tidak berbeda nyata (uji BNT, $\alpha=0,05$ ).

Tabel 4. Uji nilai tengah untuk pengaruh perlakuan terhadap lebar kepala larva C. coeruleus instar keempat

\begin{tabular}{lcc}
\hline \multicolumn{1}{c}{ Perlakuan } & Nila tengah $(\mathrm{mm})$ \\
\hline Aspidiotus destructor & $0,7^{\mathrm{a}}$ \\
Planococcus citri & $0,7^{\mathrm{a}}$ & \\
Heteropsylla cubana & $0,7^{\mathrm{a}}$ & \\
\hline Nilai tengah yang diikuti dengan huruf yang sama pada kolom yang sama tidak berbeda nyata
\end{tabular}

Nilai tengah yang diikuti dengan huruf yang sama pada kolom yang sama tidak berbeda nyata (uji BNT, $\alpha=0,05$ ).

pengaruh yang relatif sama terhadap lebar kepala larva C. coeruleus.

Pertumbuhan kepala serangga bersifat diskontinu (Gambar 1). Dalam hal ini berarti pertumbuhan serangga tidak selalu aktif. Pada periode tertentu serangga tidak mengalami penambahan ukuran kuantitatif yaitu pada saat tepat terjadi proses ekdisis (ganti kulit). Beberapa serangga dapat ditentukan jumlah fase pertumbuhannya dari satu instar ke instar berikutnya dengan menggunakan hukum Dyar (hukum pertumbuhan). Berdasarkan hukum Dyar, ukuran lebar kepala serangga yang terjadi pada setiap ekdisis mengikuti deret ukur (tumbuh secara geometris). Perbandingan ukuran lebar kepala suatu 


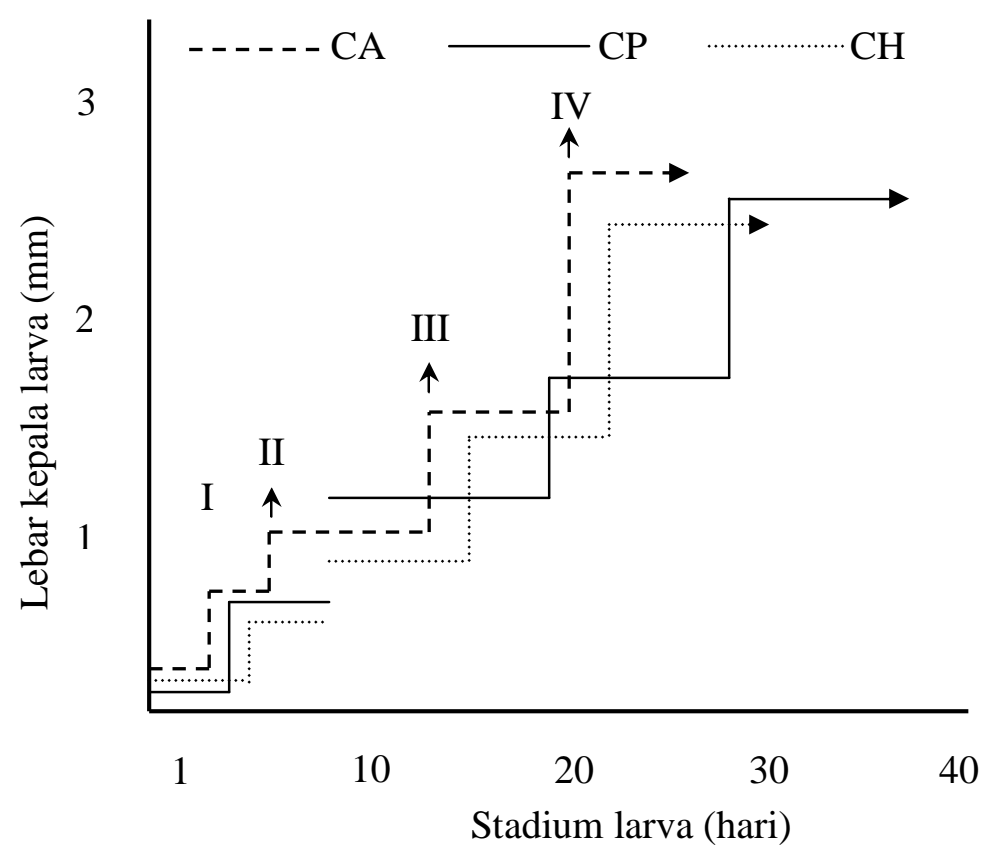

Gambar 1. Grafik pertumbuhan lebar kepala larva Curinus coeruleus Mulsant (CA: Curinus pada Aspidiotus; CP: Curinus pada Planococcus; CH: Curinus pada Heteropsylla; I: ekdisis I; II:ekdidis II; III: ekdisis III; IV: ekdisis IV).

instar dengan instar sebelumnya bersifat konstan. Nila konstanta ini umumnya berkisar dari 1,2-1,4 (Gillot, 1980).

Peningkatan ukuran lebar kepala larva C. coeruleus dari satu instar ke instar berikutnya menghasilkan angka nisbah pertumbuhan sebesar 1,4 (Tabel 5). Dengan demikian lebar kepala larva Curinus yang memangsa Aspidiotus destructor dapat digunakan untuk menduga tingkat instarnya. Tingkat instar tersebut dapat dihitung berdasarkan ukuran instar sebelumnya yang sudah diketahui lebih dahulu dan berdasarkan angka kelipatan atau angka perbandingan lebar kepala yaitu 1,4.

Lebar kepala larva $C$. coeruleus yang memangsa $P$. citri atau $H$. cubana menunjukkan nisbah pertumbuhan yang tidak konstan, yaitu mempunyai angka perbandingan nisbah pertumbuhan sebesar 1,3-1,5 (Tabel 5). Agak sulit untuk menentukan tingkat instar larva $C$. coeruleus berdasarkan angka kelipatan tersebut. Walupun angka nisbah pertumbuhannya tidak konstan, dari Tabel 5 dapat diketahui bahwa larva $C$. coeruleus pada ketiga jenis kutu tanaman mempunyai nisbah pertumbuhan yang seragam pada saat terjadi perubahan larva instar kedua menjadi instar ketiga, dengan angka kelipatan 1,4. Pada $H$. cubana makin tinggi tingkat instar atau makin besar larva $C$. coeruleus makin besar pula nisbah pertumbuhannya, dengan angka perbandingan sebesar 1,$3 ; 1,4$; kemudian 1,5 .

Stadium Larva. Hasil penelitian menunjukkan bahwa stadium larva dipengaruhi oleh jenis kutu tanaman yang dimangsa (Tabel 6). Larva C. coeruleus yang memangsa $P$. citri mempunyai stadium yang paling panjang yaitu 29,9 hari. Hal ini dapat terjadi, kemungkinan karena perbedaan aktivitas fisiologis dalam tubuh $C$. coeruleus yang memangsa kutu tanaman yang berbeda.

Pertumbuhan dan perkembangan larva dipengaruhi oleh hormon. Bentuk larva akan muncul bila hormon juana (juvenile hormone) itu ada; bentuk pupa akan muncul bila hormon itu berada dalam jumlah sedikit; dan imago akan muncul bila hormon itu tidak ditemukan. Sedangkan pergantian kulit serangga (ekdisis) dipengaruhi oleh ekdison (hormon ganti kulit). Perubahan bentuk larva yang terjadi secara bertingkat dikendalikan oleh keseimbangan waktu sekresi serta konsentrasi hormon juana dan ekdison (Wigglesworth, 1974). Dengan demikian, perbedaan stadium larva $C$. coeruleus yang memangsa kutu tanaman yang berbeda diduga karena perbedaan waktu sekresi dan konsentrasi kedua hormon tersebut 
Tabel 5. Lebar kepala larva Curinus coeruleus tiap instar pada inang yang berbeda

\begin{tabular}{|c|c|c|c|c|c|c|}
\hline \multirow{2}{*}{$\begin{array}{l}\text { Tingkat } \\
\text { instar }\end{array}$} & \multicolumn{3}{|c|}{ Lebar kepala larva $(\mathrm{mm})$ pada } & \multicolumn{3}{|c|}{ Nisbah pertumbuhan } \\
\hline & $\mathrm{A}$ & $\mathrm{P}$ & $\mathrm{H}$ & A & $\mathrm{P}$ & $\mathrm{H}$ \\
\hline Pertama & 0,3 & $\mathrm{O}, 2$ & 0,2 & & & \\
\hline Kedua & 0,3 & 0,4 & 0,3 & 1,4 & 1,5 & 1,3 \\
\hline Ketiga & 0,5 & 0,5 & 0,4 & 1,4 & 1,4 & 1,4 \\
\hline Keempat & 0,7 & 0,7 & 0,7 & 1,4 & 1,4 & 1,5 \\
\hline
\end{tabular}

Keterangan: Nisbah pertumbuhan diperoleh dengan cara membandingkan lebar kepala suatu instar C. coeruleus dengan satu tingkat instar sebelumnya. A: Aspidiotus destructor Signoret; P: Planococcus citri Risso; H: Heteropsylla cubana Crawford.

Tabel 6. Uji nilai tengah untuk pengaruh perlakuan terhadap stadium larva Curinus coeruleus

\begin{tabular}{lc}
\hline \multicolumn{1}{c}{ Perlakuan } & Nila tengah (hari) \\
\hline Aspidiotus destructor & $20,3(5,5)^{\mathrm{a}}$ \\
Planococcus citri & $29,9(5,5)^{\mathrm{b}}$ \\
Heteropsylla cubana & $22,9(4,8)^{\mathrm{a}}$ \\
\hline
\end{tabular}

Angka dalam kurung adalah hasil transformasi $\sqrt{x+0,5}$.

Nilai tengah yang diikuti dengan huruf yang sama pada kolom yang sama tidak berbeda nyata (uji BNT, $\alpha=0,05$ ).

setelah larva $C$. coeruleus memangsa kutu tanaman masing-masing.

Stadium Imago. Stadium imago atau stadium kumbang $C$. coeruleus yang diberi mangsa kutu tanaman yang berbeda jenis menunjukkan pengaruh yang sangat nyata. Stadium imago yang paling lama terdapat pada $C$. coeruleus yang diberi mangsa H. cubana (Tabel 7). Dengan demikian, peluang C. coeruleus untuk bereproduksi (berkembang-biak) dan bermigrasi (berpindah tempat) lebih besar apabila kumbang tersebut diberi mangsa $H$. cubana.

Lama Hidup. Dari hasil penelitian diketahui bahwa lama hidup $C$. coeruleus yang diberi mangsa kutu H. cubana lebih lama (177,6 hari) dibandingkan dengan yang diberi mangsa dua jenis kutu tanaman lainnya (58,5-70,6 hari). Adapun lama hidupnya pada Aspidiotus destructor tidak berbeda dengan Planococcus citri (Tabel 8). Lama hidup C. coeruleus merupakan hasil kumulatif dari penambahan stadium larva, stadium pupa, dan stadium imago (Tabel 9).
Lama hidup $C$. coeruleus pada $P$. citri relatif singkat (58,5 hari), padahal stadium larvanya relatif panjang yaitu 29,9 hari (Tabel 6). Kemungkinan hal ini terjadi karena $P$. citri mengandung bahan kimia yang berfungsi mirip hormon pada larva $C$. coeruleus. Sebagai perbandingan dapat dikemukakan hasil penelitian oleh Slama (1969) dalam Price (1975) yang menyatakan bahwa kepik Pyrrhocoris apterus yang dipelihara pada pinus balsem (Abies balsamea) tidak menjadi imago tetapi menjadi nimfa raksasa. Ternyata pada kayu pinus balsem tersebut ditemukan adanya hormon yang disebut juvabione.

Daya Memangsa. Larva $C$. coeruleus tidak memangsa A. spiniferus Seluruh kutu tersebut yang diberikan sebagai mangsa $C$. coeruleus dari instar pertama masih dalam keadaan utuh, tidak ada satupun dari kutu tersebut yang termangsa. Dengan demikian larva $C$. coeruleus tidak mendapatkan sumber energi untuk kelangsungan hidupnya sehingga akhirnya mati. Aleurocanthus spiniferus merupakan kutu tanaman yang berwarna gelap (hitam). Pada bagian 
Tabel 7. Uji nilai tengah untuk pengaruh perlakuan terhadap stadium imago Curinus coeruleus

\begin{tabular}{lc}
\hline Perlakuan & Nila tengah (hari) \\
\hline Aspidiotus destructor & $42,5(6,5)^{\mathrm{a}}$ \\
Planococcus citri & $25,4(4,5)^{\mathrm{b}}$ \\
Heteropsylla cubana & $146,6(11,9)^{\mathrm{c}}$ \\
\hline
\end{tabular}

Angka dalam kurung adalah hasil transformasi $\sqrt{x+0,5}$.

Nilai tengah yang diikuti dengan huruf yang sama pada kolom yang sama tidak berbeda nyata (uji BNT, $\alpha=0,05$ ).

Tabel 8. Uji nilai tengah untuk pengaruh perlakuan terhadap lama hidup C. coeruleus

\begin{tabular}{lc}
\hline \multicolumn{1}{c}{ Perlakuan } & Nila tengah (hari) \\
\hline Aspidiotus destructor & $70,6(1,8)^{\mathrm{a}}$ \\
Planococcus citri & $58,5(1,7)^{\mathrm{a}}$ \\
Heterop sylla cubana & $177,6(2,2)^{\mathrm{b}}$ \\
\hline
\end{tabular}

Angka dalam kurung adalah hasil transformasi $\sqrt{x+0,5}$.

Nilai tengah yang diikuti dengan huruf yang sama pada kolom yang sama tidak berbeda nyata (uji BNT, $\alpha=0,05$ ).

Tabel 9. Lama hidup C. coeruleus dari larva hingga imago pada inang yang berbeda

\begin{tabular}{lcccc}
\hline \multirow{2}{*}{ Inang } & Lama hidup & \multicolumn{3}{c}{ Stadium (hari) } \\
\cline { 3 - 5 } & (hari) & Larva & Pupa & Imago \\
\hline Aspidiotus destructor & 70,6 & 20,3 & 7,8 & 42,5 \\
Planococcus citri & 58,5 & 29,9 & 3,2 & 25,4 \\
Heteropsylla cubana & 177,6 & 22,9 & 8,0 & 146,7 \\
\hline
\end{tabular}

dorsal tubuh kutu tersebut terdapat perisai hitam berduri kaku atau kasar (Tjoa, 1956). Keadaan inilah yang mungkin dapat menghalangi proses pemangsaan larva $C$. coeruleus pada kutu A. spiniferus. Kogan (1982) mengemukakan bahwa faktor fisik seperti ciriciri morfologi yang berupa kekasaran inang dan adanya duri-duri inang dapat menjadi penghalang bagi proses makan yang normal dari suatu serangga.

Jumlah kutu tanaman yang terbanyak dimangsa oleh $C$. coeruleus adalah $H$. cubana Selama hidupnya, C. coeruleus mampu memangsa $H$. cubana rata-rata sebanyak 1.798,9 ekor. Sedangkan A. destructor dan $P$. citri rata-rata yang dimangsa $C$. coeruleus sebanyak 481 ekor dan 529,2 ekor (Tabel 10).

Daya memangsa yang tinggi dari $C$. coeruleus terhadap $H$. cubana selain didukung oleh lama hidup yang panjang dari $C$. coeruleus setelah memangsa
H. cubana (Tabel 9), juga karena C. coeruleus sebelum diintroduksi ke Indonesia, dari Hawai, merupakan predator yang paling dominan memangsa H. cubana (Soehardjan \& Oka, 1987). Dengan demikian, $C$. coeruleus tersebut memang sebelumnya sudah terbiasa memangsa $H$. cubana. Dengan berkembang-biaknya $C$. coeruleus di Indonesia (TKN - PHKLL, 1987), berarti kondisi alamiah lingkungan Indonesia tidak menjadi hambatan bagi kelangsungan hidup C. coeruleus pada hama kutu loncat lamtoro.

Dengan memperhatikan jumlah kutu tanaman yang dimangsa oleh $C$. coeruleus serta periode memangsa dari $C$. coeruleus tersebut maka dapat diketahui rata-rata jumlah kutu tanaman yang dimangsa tiap hari atau daya memangsa per hari dengan menggunakan rumus sebagai berikut: 
Tabel 10 Uji nilai tengah untuk pengaruh perlakuan terhadap daya memangsa Curinus coeruleus

\begin{tabular}{lc}
\hline Perlakuan & Nila tengah (ekor) \\
\hline Aspidiotus destructor & $481,0(2,7)^{\mathrm{a}}$ \\
Planococcus citri & $529,2(2,7)^{\mathrm{a}}$ \\
Heteropsylla cubana & $1798,9(3,3)^{\mathrm{b}}$ \\
\hline
\end{tabular}

Angka dalam kurung adalah hasil transformasi $\log \mathrm{x}$.

Nilai tengah yang diikuti dengan huruf yang sama pada kolom yang sama tidak berbeda nyata (uji BNT, $\alpha=0,05$ ).

Daya memangsa $=\frac{\text { Jumlahmangsa }(\text { ekor })}{\text { Periodememangsa }(\text { hari })}$

Periode memangsa $=$ Stadium larva + stadium imago = Lama hidup - Stadium pupa

Berdasarkan rumus tersebut, periode memangsa dari $C$. coeruleus pada $A$. destructor, $P$. citri, dan H. cubana berturut-turut adalah $62,7,55,2$, dan 169,6 hari. Dengan demikian jumlah kutu tanaman masingmasing yang dimangsa $C$. coeruleus rata-rata per hari secara berturut-turut adalah 7, 9, dan 10 ekor per hari.

Keadaan tersebut dapat berarti bahwa daya mangsa $C$. coeruleus terhadap A. destructor atau $P$. citri tidak berbeda jauh dengan daya mangsa C. coeruleus terhadap H. cubana. Menurut Supartha \& Susila (2001), meskipun $H$. cubana mampu meloncat, $C$. coeruleus masih mampu mengejarnya. Oleh karena itu kalau kutu-kutu tanaman tersebut tidak dapat meloncat dan tidak lari niscaya C. coeruleus akan menangkapnya dengan lebih mudah.

Introduksi predator C. coeruleus dari Hawai sengaja dilakukan untuk pelaksanaan pengendalian hayati terhadap $H$. cubana yang menyerang tanaman lamtoro (TKN-PHKLL, 1986). Kenyataan bahwa C. coeruleus memangsa kutu tanaman selain H. cubana menunjukkan tingkat spesifikasinya tidak tinggi. Dalam hal ini telah diketahui bahwa pada mulanya, C. coeruleus pada tahun 1922 diintroduksi dari Mexico ke Hawai dengan tujuan untuk mengendalikan hama kutu dompolan (mealy bug) pada tanaman kelapa (NFTA, 1986).

Dalam penelitian ini diketahui bahwa C. coeruleus tidak hanya dapat memangsa kutu loncat lamtoro saja, tetapi dapat juga memangsa dua jenis kutu tanaman lainnya. Sifat $C$. coeruleus yang dapat memangsa beberapa jenis inang atau kutu tanaman berarti C. coeruleus bersifat oligofagus. Oka \& Bahagiawati (1988) mengemukakan bahwa dengan adanya sifat polifagus maka $C$. coeruleus Mulsant dapat efektif menekan secara parsial terhadap H. cubana. Walaupun demikian, kedaan ini dapat menguntungkan bagi kelangsungan hidup C. coeruleus di alam. Bila salah satu inang atau kutu tanaman tersebut sudah tidak tersedia lagi di alam maka $C$. coeruleus masih bisa bertahan hidup pada kutu tanaman lain yang masih tersedia di sekitarnya sebagai inang alternatifnya.

Musuh alami lain yang mempunyai harapan baik sebagai agen pengendalian hayati adalah sejenis parasitoid dari Hawai pula dengan nama ilmiah Psyllaephagus sp. nr. rotundiformis (Howard). Parasitoid ini diimpor ke Hawai oleh Departemen Pertanian Hawai dari India Barat. Studi tentang pelepasan terbatas parasitoid tersebut menunjukkan bahwa hasilnya efektif untuk mengendalikan $H$. cubana. Karena tingkat spesifikasi inannya tinggi (hanya memngsa Heteropsylla) maka diharapkan parasitoid dapat membantu penurunan populasi kutu loncat lamtoro secara nyata, terutama bila kumbang C. coeruleus tidak dapat bertahan hidup dengan baik (Oka \& Bahagiawati, 1988).

\section{SIMPULAN}

Perkembangan hidup C. coeruleus dipengaruhi oleh jenis kutu tanaman yang dimangsanya, kecuali dalam hal lebar kepala larva C. coeruleus. Kumbang C. coeruleus tidak dapat bertahan hidup pada kutu medalion jeruk (Aeurocanthus spiniferus Quaintance). Kumbang $C$. coeruleus mempunyai daya memangsa yang tinggi terhadap Heteropsylla cubana Crawford. Selain dapat memangsa $H$. cubana, $C$. coeruleus juga dapat memangsa $A$. destructor dan $P$. citri. Daya memangsa dari $C$. coeruleus terhadap $H$. cubana lebih besar daripada terhadap A. destructor, atau P. citri. 


\section{DAFTAR PUSTAKA}

Gillot, C. 1980. Entomology. Plenum Press, New York.

Hoy, M. A. 1985. Improving Establishment of Arthropod Natural Enemies.Pages 151-166 in: Hoy, M. A. \& D. C. Herzog, eds. Biological Control in Agricultural IPM Systems. Academic Press, Inc., Orlando, Florida.

Kogan, M. 1982. Plant Resistance in Pest Management. Pages 93-134 in: Metcalf, R. L. and W. H. Luckmann, eds. Introduction to Insect Pest Management. John Wiley \& Sons. New York.

NFTA (Nitrogen Fixing Tree Association). 1986. Leucaena Psyllid-The Problem and Proposed Solution. NFT Highlihts. NFTA 86-01 Feb. 1986.

Oka, I. N. \& A. H. Bahagiawati. 1986. Hama Baru Heteropsylla sp. (Homoptera: Psyllidae) Menyerang Lamtoro di Indonesia. Informasi Kilat. Badan Penelitian dan Pengembangan Pertanian, Jakarta. $9 \mathrm{hlm}$.

Oka, I. N. \& A. H. Bahagiawati. 1988. Comprehensive Program towards Integrated Control of Leucaena Psyllid, A New Insect Pest of Leucaena Trees in Indonesia. Indon. Agric. Res. \& Dev. Jour. 10(1): 23-30.

Shepard, M. \& D. C. Herzog. 1985. Soybean: Status and Current Limits to Biological Control in the Southern U.S. Pages 557-574 in: Hoy, M. A. \& D. C. Herzog, eds. Biological Control in Agricultural IPM Systems. Academic Press, Inc., Orlando, Florida.
Soehardjan, M \& I. N. Oka. 1987. Workshop on Biological and Genetic Control of the Leucaena Psyllid. Bull. Littro. 1(2): 110116.

Sosromarsono, S. 2005. Biological Control of Agricultural Pests in Indonesia: The Last Six Decades of Experience. Pages 141-165. in: Soemodihardjo, S. \& S. D. Sastrapraja, eds. Six Decades of Science and Scientists in Indonesia. NATURINDO (Naturae Indonesiana).

Price, P. W. 1975. Insect Ecology. John Wiley \& Sons, New York.

Supartha, I. W. \& I. W. Susila. 2001. Uji Pemangsaan Curinus coeruleus Mulsant (coleoptera: Coccinellidae) terhadap Diaphorina citri Kuw. (Homoptera: Psyllidae) dan Heteropsylla cubana Crawford (Homoptera: Psyllidae). Agritrop (jurnal Ilmu-Ilmu Pertanian), 20(1): 5-9.

Tjoa, T. M. 1956. Memberantas Hama Djeruk. Pusat Djawatan Pertanian Rakjat, Djakarta.

TKN_PHKLL (Tim Kerja Nasional Penanggulangan Hama Kutu Loncat Lamtoro). 1986. Kutu Loncat Lamtoro Heteropsylla spp. (Homoptera: Psyllidae), Hama pada Tanaman Lamtoro di Indonesia. Lembaran informasi Teknis No.1, Juli 1986. 7 hlm.

TKN_PHKLL (Tim Kerja Nasional Penanggulangan Hama Kutu Loncat Lamtoro). 1987. Pedoman Pembiakan dan Pelepasan Curinus coeruleus Mulsant Pemangsa (Predator) Hama Kutu Loncat Lamtoro Heteropsylla spp. Lembaran informasi Teknis No. 3, Februari 1987. 16 hlm.

Wigglesworth, V. B. 1974. Insect Physiology. Chapman and Hall, London. 